\title{
Removal of reactive dyes by quaternized coconut husk
}

\begin{abstract}
Coconut husk modified through the use of N-(3-chloro-2-hydroxypropyl)trimethylammonium chloride was evaluated for its ability to remove reactive dyes from aqueous solution. Sorption of dyes was $\mathrm{pH}$ dependent and favorable sorption occurred at low $\mathrm{pH}$. In contrast, natural coconut husk showed very little uptake of these reactive dyes. The maximum sorption capacities of the modified coconut husks for Reactive Blue 2, Reactive Yellow 2, Reactive Orange 16 and Reactive Blue 4 were 128.9, 182.2, 254.5 and $423.7 \mathrm{mg} / \mathrm{g}$ respectively. Column experiments using textile effluent showed that the reactive and disperse dyes in the effluent could be successfully removed.
\end{abstract}

Keyword: Sorption; Reactive dyes; Quaternized coconut husk; Textile effluent 